Article

\title{
Development of Web GIS-Based VFSMOD System with Three Modules for Effective Vegetative Filter Strip Design
}

\author{
Youn Shik Park ${ }^{1}$, Bernie A. Engel ${ }^{1}$, Yongchul Shin ${ }^{2}$, Joongdae Choi ${ }^{3}$, Nam-Won Kim ${ }^{4}$, \\ Seong-Joon Kim ${ }^{5}$, Dong Soo Kong ${ }^{6}$ and Kyoung Jae Lim ${ }^{3}$ *
}

1 Agricultural Biological Engineering, Purdue University, West Lafayette, IN 47907, USA;

E-Mails: park397@purdue.edu (Y.S.P.); engelb@purdue.edu (B.A.E.)

2 Department of Biological and Agricultural Engineering, Texas A\&M University, College Station, TX 77843, USA; E-Mail: ycshin@neo.tamu.edu

3 Regional Infrastructure Engineering, Kangwon National University, Chuncheon, Gangwon 200-701, Korea; E-Mail: jdchoi@kangwon.ac.kr

4 Korea Institute of Construction Technology, 2311 Daewha Ilsan-Gu, Goyang-Si, Gyeonggi-Do 411-712, Korea; E-Mail: nwkim@kict.re.kr

5 Konkuk University, 120 Neungdong-ro, Gwangjin-gu, Seoul 143-701, Korea; E-Mail: kimsj@konkuk.ac.kr

6 Department of Biological Sciences, Kyonggi University, Department of Biological Sciences, Kyonggi University, 71, Chungjeong-Ro 2-Ga, Seodaemun-Gu, Seoul 120-702, Korea; E-Mail: dskong@kyonggi.ac.kr

* Author to whom correspondence should be addressed; E-Mail: kjlim@kangwon.ac.kr; Tel.: +82-33-250-6468; Fax: +82-33-251-1518.

Received: 25 June 2013; in revised form: 26 July 2013 / Accepted: 29 July 2013 /

Published: 7 August 2013

\begin{abstract}
In recent years, Non-Point Source Pollution has been rising as a significant environmental issue. The sediment-laden water problem is causing serious impacts on river ecosystems not only in South Korea but also in most countries. The vegetative filter strip (VFS) has been thought to be one of the most effective methods to reduce the transport of sediment to down-gradient area. However, the effective width of the VFS first needs to be determined before VFS installation in the field. To provide an easy-to-use interface with a scientific VFS modeling engine, the Web GIS-based VFSMOD system was developed in this study. The Web GIS-based VFSMOD uses the UH and VFSM executable programs from the VFSMOD-w model as core engines to simulate rainfall-runoff and sediment trapping. To provide soil information for a point of interest,
\end{abstract}


the Google Map interface to the MapServer soil database system was developed using the Google Map API, Javascript, Perl/CGI, and Oracle DB programming. Three modules of the Web GIS-based VFSMOD system were developed for various VFS designs under single storm, multiple storm, and long-term period scenarios. These modules in the Web GIS-based VFSMOD system were applied to the study watershed in South Korea and these were proven as efficient tools for the VFS design for various purposes.

Keywords: filter strip; sediment; water quality; VFSMOD; Web GIS VFSMOD

\section{Introduction}

In recent years, sediment transport in runoff has been considered one of the serious environmental problems worldwide. Especially, accelerated soil erosion within watersheds is quite serious worldwide, and it is difficult to estimate economic and environmental impacts due to soil erosion because it is occurring in large areas and is a complex process associated with rainfall. Many kinds of human activities, such as mining, construction, and agricultural activities disturb the land surfaces, resulting in accelerated erosion. Soil erosion from agricultural areas is typically higher than that from non-agricultural areas [1]. Soil loss is one of the major causes incurring sediment-laden water in South Korea Sediment-laden water problem arises when significant amounts of sediment flow into streams with runoff or surface flow. The sediment-laden water can cause serious problems such as disruption of the aquatic ecosystems, reduction of the design life of dams, pulling down water resources worth, and so on. The important fact is that the sediment-laden water is a natural phenomenon, thus it cannot be prevented perfectly, but it can be reduced so as to avoid these serious problems in watersheds. There are so many methods to manage and prevent this sediment-laden water problem such as sediment basins, erosion control dams, grit chamber, reservoir, or debris barrier. Vegetative filter strip (VFS) has been increasingly used because of its environment-friendly and economical aspects. The VFS is designed to remove not only sediment, but also other pollutants such as nutrients and pathogens from surface water runoff by filtration, deposition, infiltration, adsorption, absorption, decomposition, and plant uptake [2]. Reducing the velocity of runoff from source areas such as farmland or agricultural areas, the VFS causes sediment to be deposited. Usually located at edge of agricultural areas and adjacent to streams or drainage ditches, the VFS traps sediment effectively, and moreover, the VFS has been shown to effectively remove the soluble pollutants and chemicals from runoff $[3,4]$. In addition, there is a need to simulate VFSs to be effective design before installation to the fields. According to the study by Gharabaghi et al. [5], sediment was reduced with different types of the VFS with reductions ranging from 50 to $98 \%$ in the experimental field. As such, the effect of the VFS needs to be studied for effective width design of the VFS before being set up in a field. Therefore a model, capable of calculating the effective VFS width, is needed before being set up at the field. In addition, Web-based models have many advantages over desktop-based models, even though many kinds of desktop-based models are used in many studies. Recently, Web-based techniques are less expensive, more efficient and lately have been the target of the most development [6]. Web-based models do not need to be installed at personal desktop, or even updated. However, the desktop-based 
models should be installed, need to be updated; moreover, different results can be calculated without timely updates [7,8]. Especially, desktop-based models require users to prepare many kinds of input data, which is sometimes very difficult for even experienced users. The Vegetated Filter Strip model (VFSMOD), developed by Munoz-Carpena and Parsons [2], is a desktop-based model. Thus it requires many various input data as it considers various conditions of upland field and the VFS. Although this could be merit of the desktop-based VFSMOD system, but demerit because of extensive input data requirement.

The objectives of this study are: (1) to develop Web GIS-based VFSMOD system [9], utilizing the VFSMOD as a core engine; and (2) to apply the Web GIS-based VFSMOD system to design effective width of VFS at the study watershed using Web GIS-based VFSMOD system.

\section{Literature Review}

One of the Best Management Practices (BMP) promoted by state and federal agencies in the USA to protect water resources from non-point source pollution is the installment of VFS. The VFS is land areas of planted vegetation, usually grasses, installed at the edge of agricultural areas, or animal production facilities to filter nutrient, sediment, organics, pathogens, and pesticides from agricultural runoff before it reaches a water system such as streams or rivers. The VFS can be effective in reducing sediment and other pollutants [10], however the effectiveness is dependent on site-specific factors in the field $[11,12]$. These studies reported that the VFS can reduce pollutant loads by reducing velocity of surface flow from agricultural areas and causing infiltration. The performance of VFS is affected by many parameters, such as slope, volume of runoff, soil type, and vegetation characteristics. The VFS is a dynamic system with many parameters; in addition these time-variant factors can affect the VFS performance. Therefore, site-specific management methods need to be evaluated and developed for successful functioning of the VFS. These important and various factors affecting VFS performance have to be considered by the Vegetated Filter Strip model (VFSMOD), developed by Munoz-Carpena and Parsons [2]. The VFSMOD system is a desktop-based model, and it requires many input data as it considers various conditions of field and VFS. The field-scale, mechanistic, storm-based VFSMOD is designed to simulate the hydrograph by rainfall and sediment inflow from an adjacent upper field [13]. The model calculates the outflow, infiltration, and sediment reduction through VFS from adjacent upper field [14]. As such, the model can be used to predict sediment transport through VFS, simulates outflow and sediment reduction in VFS based overland flow hydraulics and infiltration into the soil layer [15]. The VFSMOD was successfully tested with natural events with North Carolina Piedmont data [2] and Coastal Plain [16]. Researchers at the University of Guelph, in Canada, have tested the model with field experimental data [17]. They reported good agreement between model simulations (infiltration, outflow, and sediment trapping) and measured values, moreover the results of the model has been used to improve the Soil and Water Assessment Tool (SWAT) $[18,19]$.

The VFSMOD model requires input data [20]:

Source Area Parameters:

- Rainfall event and Runoff

- rainfall
Filter Strip Parameters:

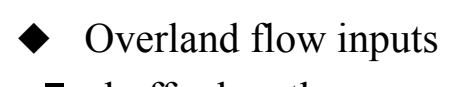

- buffer length 
- storm duration

- curve number

- storm type

- Source Area

- length along area

- slope as a fraction

- area

- Erosion Parameter

- soil erodibility

- soil type

- percent organic matter

- particle class diameter

- crop factor

- practice factor
- width of the strip

- Soil properties

- vertical saturated $\mathrm{K}$

- initial water content

- saturated water content

- Buffer vegetation properties

- spacing for grass stems

- height of grass

- roughness

This extensive data requirement indicates that the VFSMOD system allows consideration of various field conditions.

\section{Development of Web GIS-Based VFSMOD}

\subsection{Development of Input Interface of Web GIS-Based VFSMOD System}

In this study, the Web Geographic Information System-based (GIS-based) VFSMOD system was developed to simulate VFS performance and calculate sediment reduction effect of the VFS. Three modules of the Web GIS-based VFSMOD systems were developed (Figure 1). "Single Storm Event Analysis (SSEA) module", "Multiple Storm Events Analysis (MSEA) module", and "HUFF \& SCS UH-based VFS Design module" using Huff's rainfall distribution (HUFF) and the Soil Conservation Service Unit Hydrograph (SCS UH) are provided in the Web GIS-based VFSMOD system. The Web GIS-based VFSMOD system is comprised of a client-side interface, server-side pre- and post-processors, and the UH and VFSM executable programs from the VFSMOD-w model (Figure 2).

The client-side interface of Single Storm Event Analysis (SSEA) was developed with the languages of HTML, DHTML, Perl/CGI, Java script, Google Map API, and Map Sever Web GIS application. The input interface is comprised of "Rainfall Event and Runoff", "Source Area", "Erosion Parameter", "Rainfall Factor", "Buffer Dimension", "Green-Ampt Infiltration Parameter", and "Vegetation Parameter" section (Figure 3). The range of each input data and available/recommended values are provided in tabular format for users to understand and choose proper input values. Thus, with limited input data, users can run the VFSMOD system and analyze the output for site-specific design of filter strip with several clicks of the mouse button, which was not possible with the desktop-based VFSMOD (Figure 3). In addition, many kinds of input data are provided and recommended with HTML tables for user to use those values directly and easily (Figure 4). 
Figure 1. Single Storm Event Analysis module (SSEA), Multiple Storm Events Analysis (MSEA) module, and HUFF \& SCS UH-based VFS design module in the Web GIS-based VFSMOD system [9].

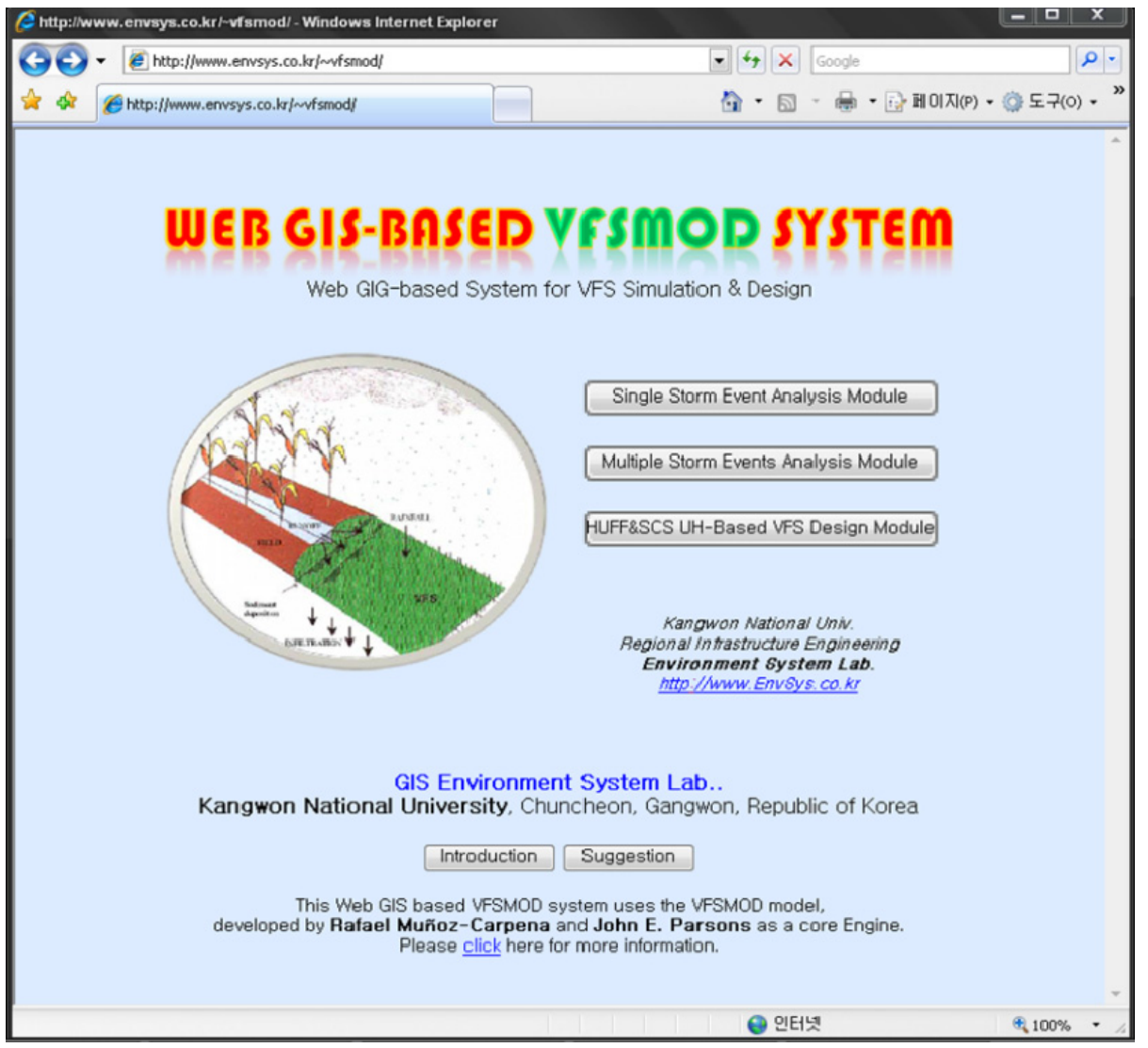

Figure 2. Overview of Web GIS-based VFSMOD system.

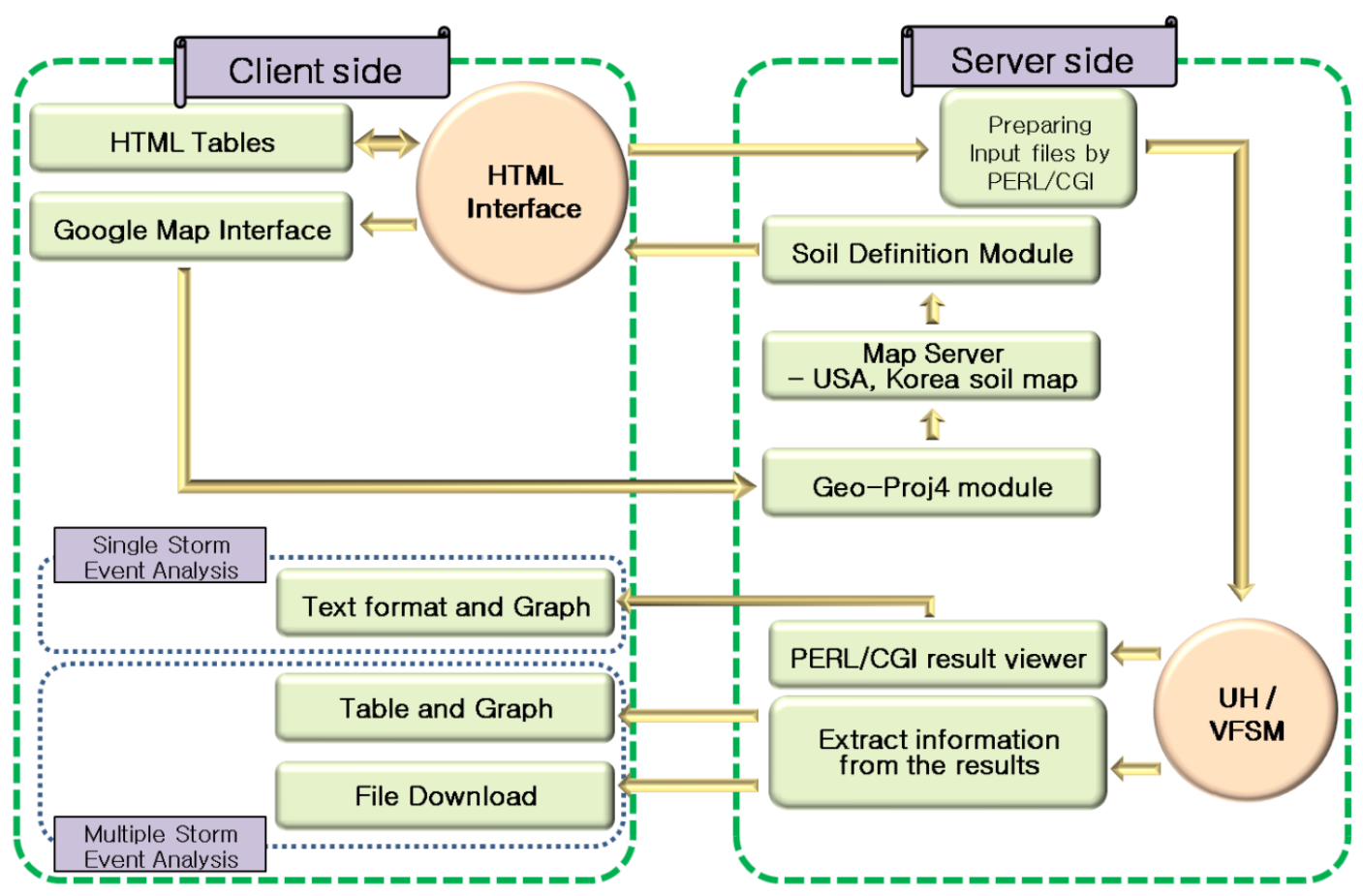


Figure 3. Single Storm Event Analysis (SSEA) module in Web GIS-based VFSMOD system.

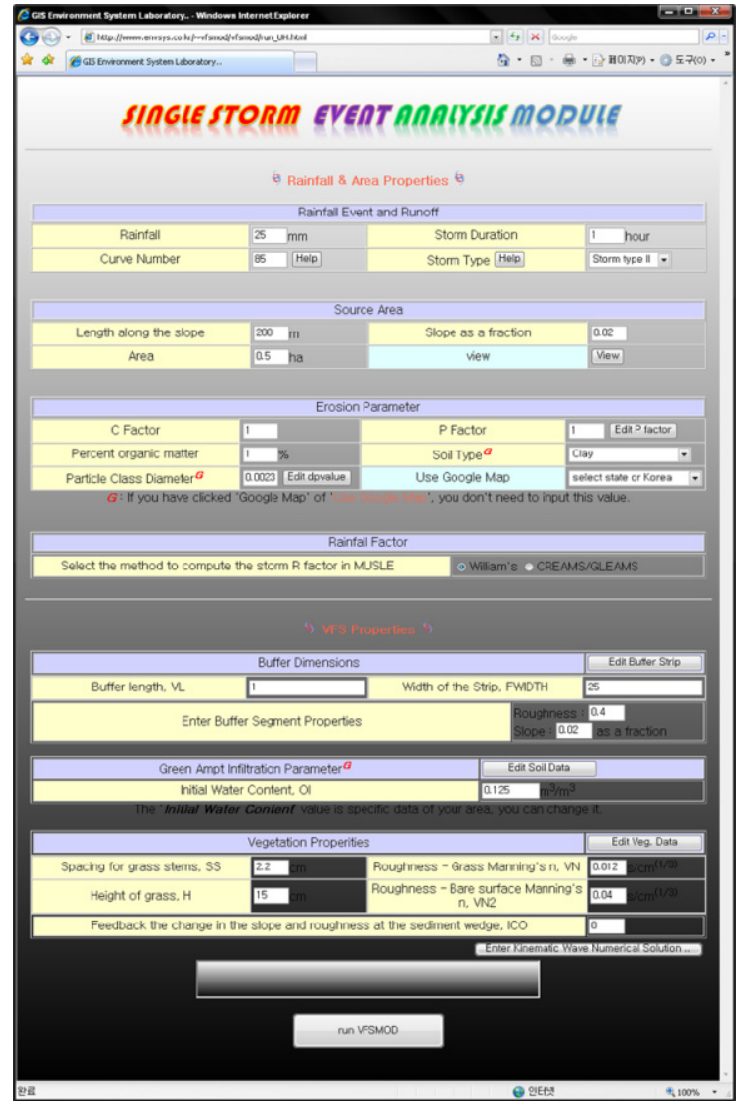

Figure 4. HTML reference tables for various input parameters.

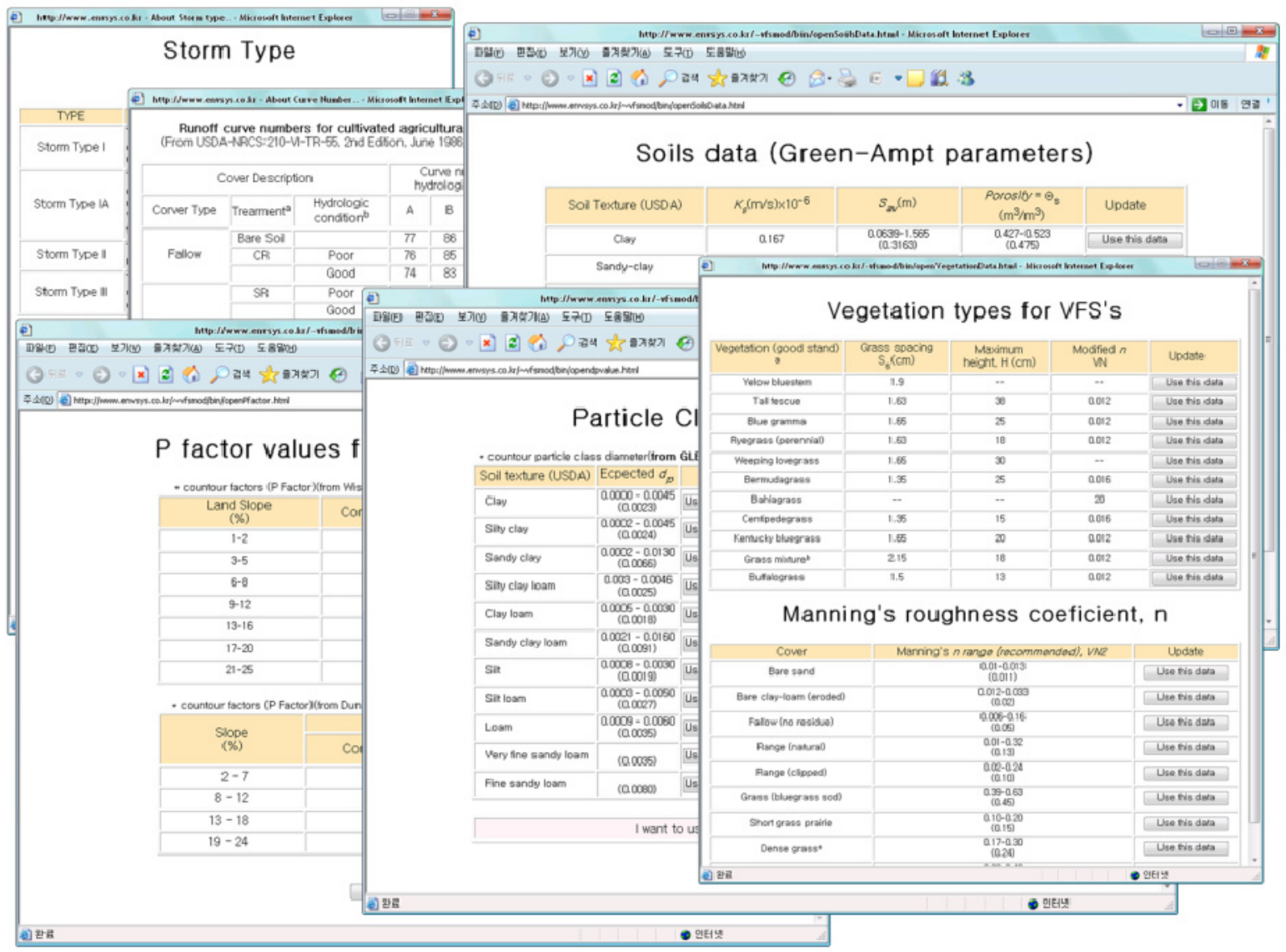




\subsection{Development of Google Map Interface to MapServer Soil Database}

Although the Web GIS based interface helps model users run the VFSMOD with less input data and ease-of-use interface, the users need to prepare soil property of the area of interest, which is sometimes time-consuming and hard to find for novice users. Thus, the Google Map interface was developed to query soil properties of the point of interest through server-side MapServer application. The soil maps for South Korea and Alabama (AL), Indiana (IN), Illinois (IL), Kentucky (KY), Michigan (MI), Mississippi (MS), Tennessee (TN), and Wisconsin (WI) STATSGO soil database are stored at server-side in TM/UTM projections for automatic soil property extraction from the Latitude-Longitude-based Google Map interface. For this, Geo-Proj4 module [21] was used for on-the-fly projection for automatic soil property query from Lat/Long-based Google Map interface to TM/UTM soil data stored in MapServer application. The soil type, particle class diameter, vertical saturated $\mathrm{K}$, average suction head at the wetting front, saturated water content information are extracted with this Google Map interface. With this Google Map-based Web GIS interface, the complex soil input data are prepared within a second on-the-fly (Figure 5). The work is underway to extend this to 48 states for practical application of VFSMOD system in the continental USA.

Figure 5. Google Map interface for extracting various soil input parameters; (a) South Korea; (b) AL, IN, IL, KY, MI, MS, TN, and WI, USA.
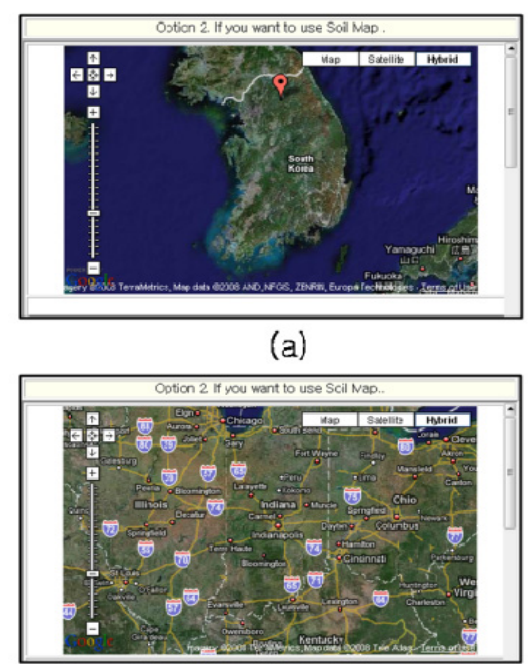

(b)

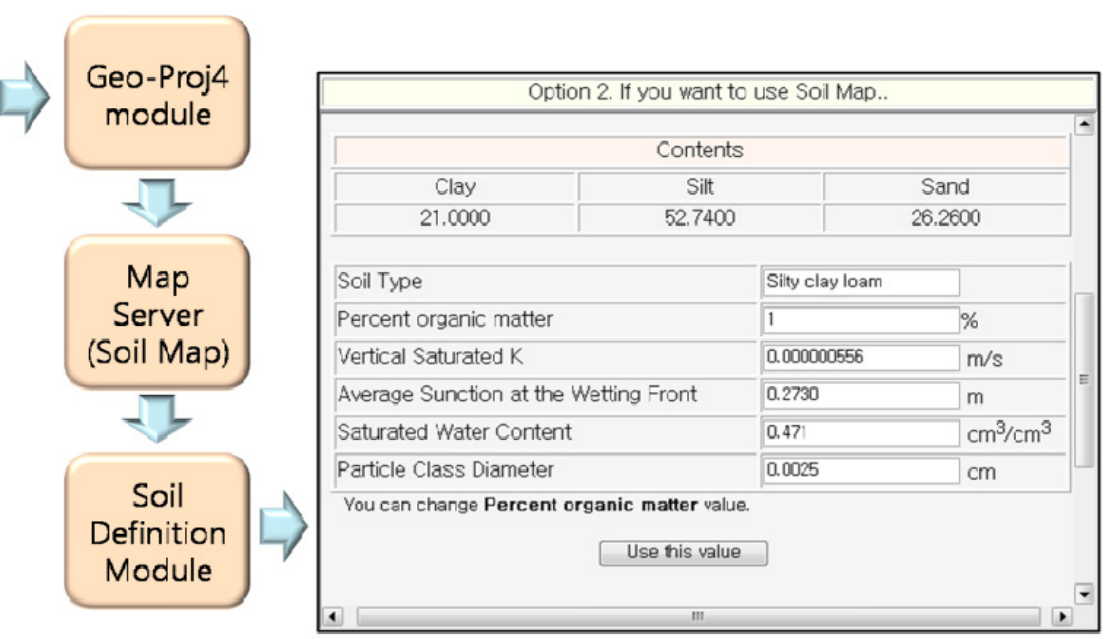

\subsection{Multiple Storm Events Analysis (MSEA) Module}

As shown above, the Single Storm Event Analysis (SSEA) module in the Web GIS-based VFSMOD system can be used to simulate the effects of the VFS with an easy-to-use interface. However, model users have to run this SSEA module repetitively to determine the effective VFS width in a given field, which are very much tedious jobs if users have to design effective VFS width for various fields under various rainfall conditions in the watershed. The Single Storm Event Analysis 
(SSEA) module requires various files, described earlier, which are INP, IKW, ISO, IGR, ISD, IRN, and IRO files. The INP and IKW files have the rainfall and VFS width values, respectively. Thus, a number of INP and IKW files are needed to simulate various filter strip scenarios in the field. In this study "Multiple Storm Events Analysis (MSEA) module" was developed to automate the SSEA for up to 45 times with five INP files and nine IKW files. Most of the functions are similar with SSEA module, but maximum five design storm values and maximum nine VFS width values can be simulated. The MSEA module in the Web GIS-based VFSMOD generates the INP and IKW files with user-provided rainfall and VFS width values, The Multiple Storm Events Analysis (MSEA) module uses these INP and IKW files with other ISO, IGR, ISD, IRN, and IRO files for the model batch runs under given conditions (Figure 6). The Google Map interface to the MapServer soil database is also provided in the MSEA module.

Figure 6. Multiple Storm Events Analysis (MSEA) module in the Web GIS-based VFSMOD system.

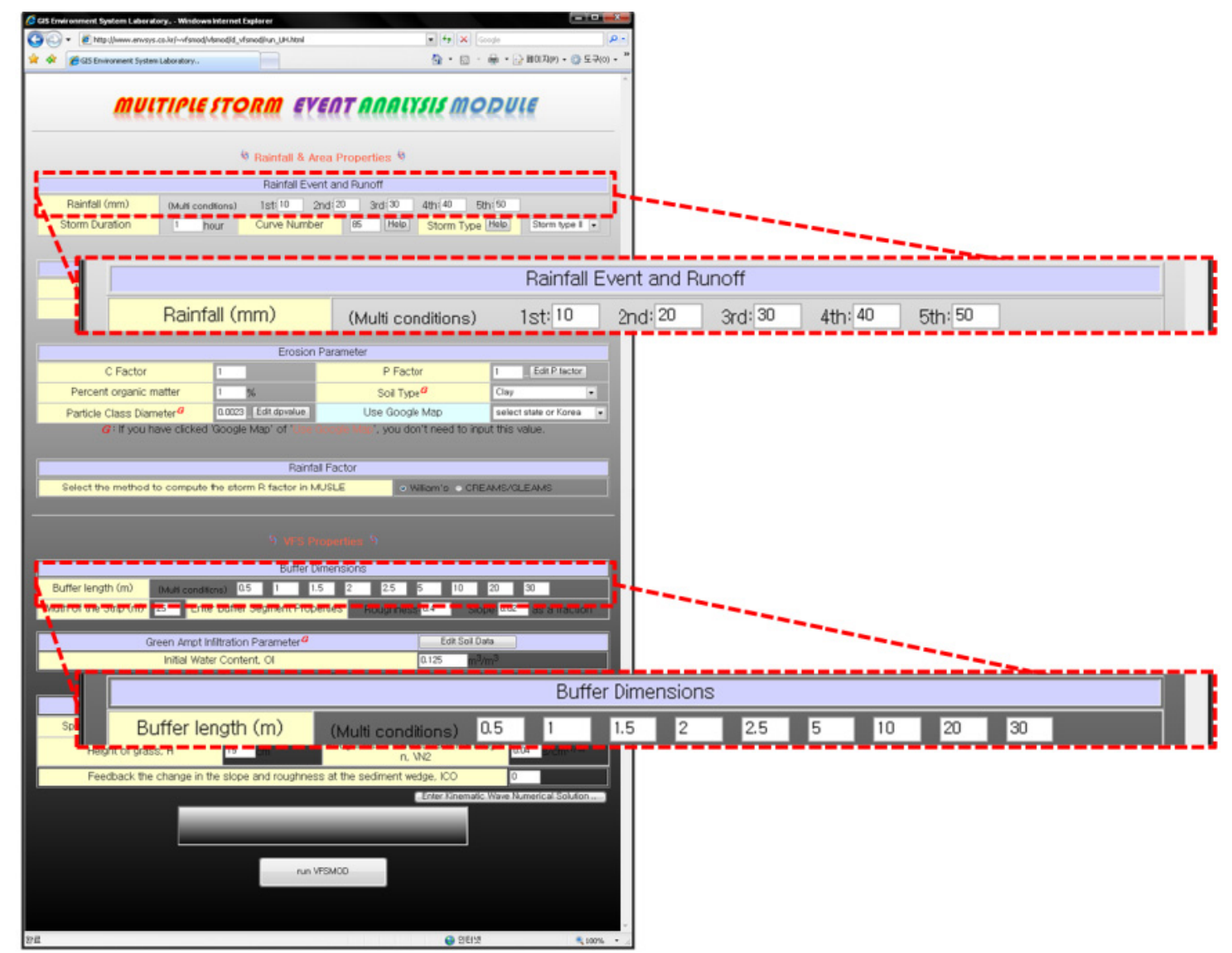

\subsection{HUFF \& SCS UH-Based VFS Design Module}

\subsubsection{Modified Rainfall Module Using Huff Rainfall Distribution Curves}

In the design of hydraulic structures, selecting a design storm event is one of the most important decisions. Depending on the design storm distribution methods employed, the rainfall distribution varies significantly, resulting in huge differences in calculated dimension of hydraulic structures. The Huff method has been widely used in many countries to generate design storm for hydraulic structure 
design. Huff analyzed the storms of 11 year rainfall data collected in the Illinois, USA to develop the Huff rainfall distribution curves. The rainfall data were non-dimensional form such as the ratio of total storm depth and accumulated depth of precipitation, and the ratio of each time and time of duration. The storms were classified into four categories depending on the peak rainfall intensity time in the 1st, $2 \mathrm{nd}, 3 \mathrm{rd}$, 4th quartile of the rainfall duration. The distribution of rainfall is very important in design process, because the rainfall affects runoff generation. This means that the dimensions of hydraulic structures can be different under the same magnitude of design storm values. Usually, the 4th quartile distribution method of Huff is being used in design of hydraulic structures to reflect the worst-case scenario. Also, the Huff 1st, 2nd, and 3rd quartile distribution methods are also being used in design of hydraulic structures. For these reasons, the Huff method was developed and integrated with Web GIS-based VFSMOD system. For this, HUFF Rainfall Distribution Curves (HUFF RDC), a sub-module was developed and integrated to Web interface in this study to allow users to design the VFS under various rainfall conditions, i.e., 4th quartile for worst case condition, and other 1st, 2nd, and 3rd quartile options (Figure 7).

Figure 7. HUFF \& SCS UH-based VFS design module using Huff method.

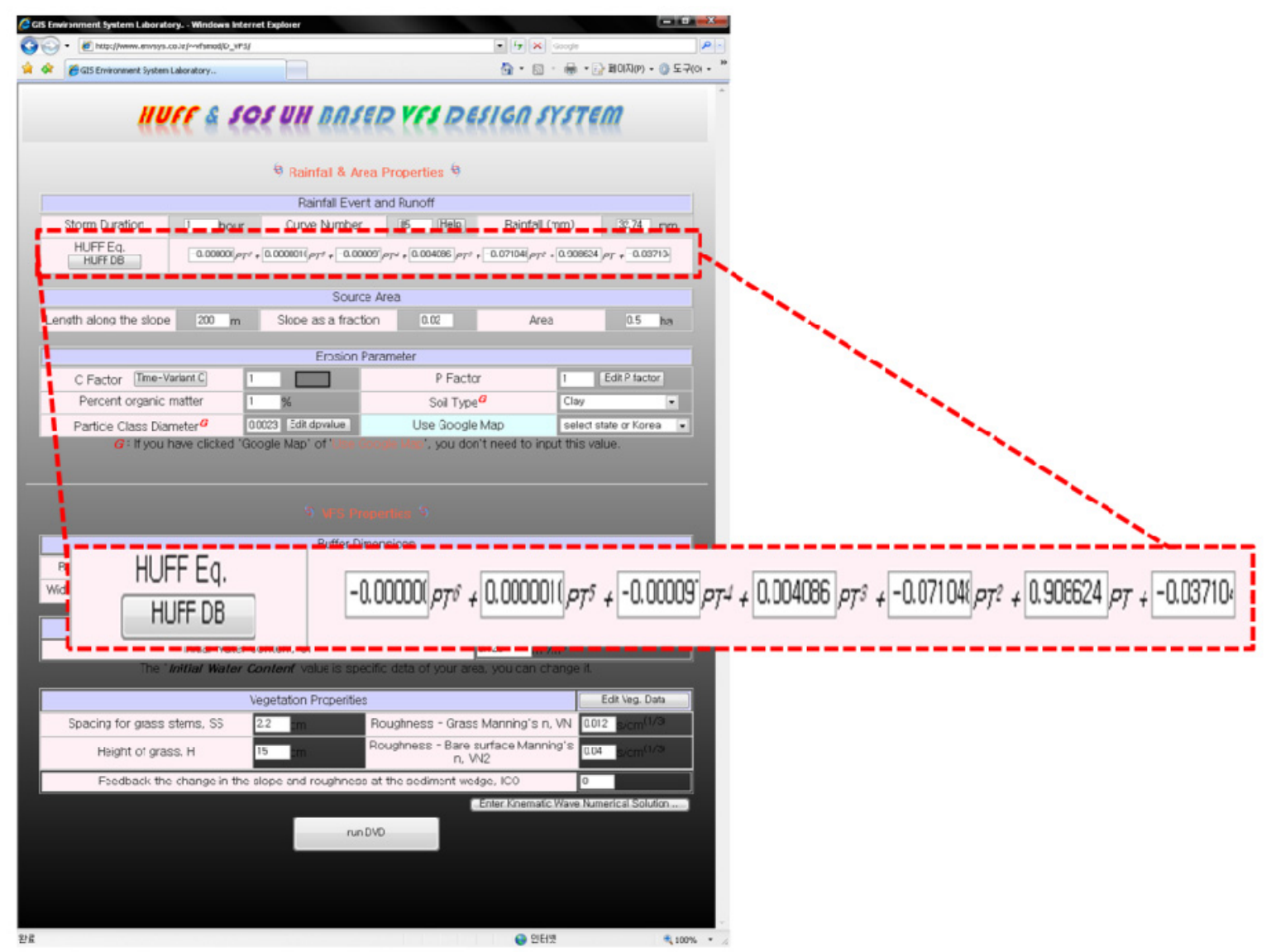

\subsubsection{Development of SCS Unit Hydrograph Module}

The Soil Conservation Service (SCS, currently Natural Resources Conservation Service; NRCS) unit hydrograph method is one of the most useful methods for deriving unit hydrograph. Total volume 
$\mathrm{V}$ can be defined with Equation 1 using $\mathrm{Q}_{\mathrm{p}}$ (peak flow, $\mathrm{m}^{3} / \mathrm{sec}$ ), $\mathrm{T}_{\mathrm{R}}$ (time to peak, hour), and B (recession limb time, hour).

$$
\mathrm{V}=\frac{Q_{P} \times T_{R}}{2}+\frac{Q_{P} \times B}{2}
$$

The B (recession limb time, hour) is defined as Equation 2; also peak flow $\left(\mathrm{Q}_{\mathrm{p}}, \mathrm{m}^{3} / \mathrm{sec}\right)$ is defined as Equation 3 using $\mathrm{A}$ (watershed area; $\mathrm{km}^{2}$ ) and $\mathrm{T}_{\mathrm{R}}$ (time to peak).

$$
\begin{gathered}
\mathrm{B}=1.67 \times T_{R} \\
Q_{P}=2.08 \times \frac{A}{T_{R}}
\end{gathered}
$$

The time to peak $\left(T_{R}\right)$ is defined as Equation 4 using D (storm duration, hour), L (length of the longest drainage path, m), S (1000/CN (Curve Number) - 10), and Y (the average watershed slope, \%).

$$
T_{R}=\frac{D}{2}+\frac{(0.3048 \times L)^{0.8} \times(S+1)^{0.7}}{1900 \times Y^{0.5}}
$$

In this study, the SCS synthetic unit hydrograph module was developed and used to derive hydrograph from the sources area using the unit hydrograph and distributed rainfall data by the Huff method. The A, L, S, Y, CN, and slope values, provided in source area input interface, are used to derive 10-minute unit hydrograph. This unit hydrograph is multiplied by the excess rainfall data for each 10-minute interval for hydrograph from the source area.

\subsubsection{Development of Time-Variant USLE C Factor Module}

Both the desktop-based VFSMOD-w and the Web GIS-based VFSMOD System simulate a sediment balance with sediment generated from the Source Area. Thus, field conditions in the VFS and source area need to be considered simultaneously. One of the most sensitive factors affecting sediment generation at the source areas is the Universal Soil Loss Equation Crop management (USLE C) factor. The USLE C factor is dependent on crops types as well as land cover condition at the source area. The USLE $C$ factor changes through the year, because the leaf areas and canopy height increase with time until the crop reaches maturity and harvest. Accordingly, sediment generation is affected by crop growth stage at the source areas. Therefore, sediment trapping efficiency (TE) can be varied with crop growth at the source areas. Thus, the Time-Variant USLE C factor module was developed using the database developed by Park et al. (2008) [22] and integrated with the HUFF \& SCS UH-based VFS Design module in this study. The sediment trapping efficiencies are calculated by the module at 10-day intervals of the year. The Time-Variant USLE C factors of 30 crops are stored at the server-side as shown in Figure 8 to enable simultaneous simulation of USLE $\mathrm{C}$ factor values. This Time-Variant USLE C factor module considers not only one crop grown, but also multiple cropping in a year. 
Figure 8. Time-Variant USLE C factor DB of 30 major crops.

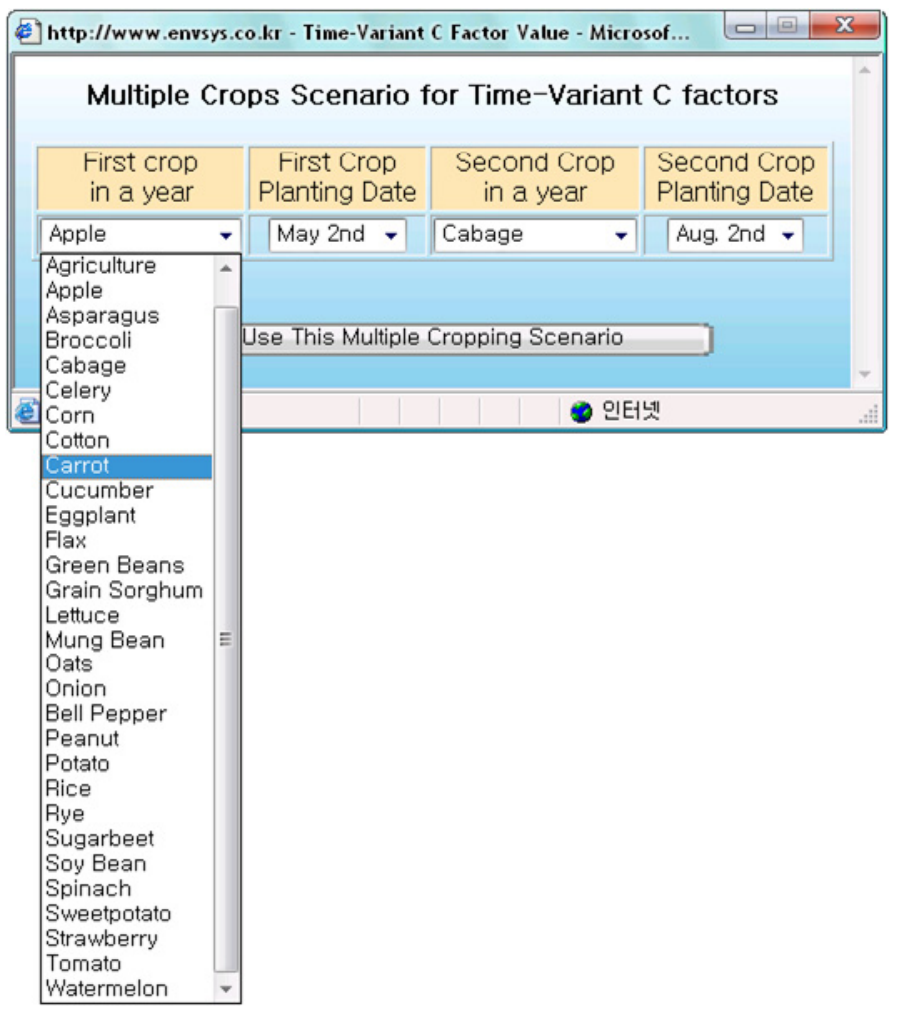

\subsection{Development of Output Interface of Web GIS-Based VFSMOD System}

Once the model is run, the post processors at the server-side compile the model output and generate tabular and graphical output for easy understanding of the simulation results. For the Single Storm Event Analysis (SSEA) module, graphs of hyetograph, hydrograph, and sediment are generated using Java applet and Perl/CGI programming as shown in Figure 9a. In addition, other output files from the UH and VFSM are provided in textural format for further analysis if needed. With the output interface, the Web GIS-based VFSMOD users can quickly easily find the effects of the VFS dimensions on its performance under user-specified conditions.

The trapping efficiencies under various VFS width and design storm events are provided in tabular format. The output can be downloaded into a desktop spreadsheet program for further analysis and reporting purpose. The trapping efficiencies are provided in graphical format also with the cross-hair interface for quick identification of effective VFS width or trapping efficiency under a certain condition (Figure 9b).

For HUFF \& SCS UH-based VFS Design Module, the post processors extract sediment trapping efficiencies from numerous runs considering crop growth and crop management over the year. The sediment trapping efficiencies are affected by rainfall-runoff and time-variant $\mathrm{C}$ factor values in the source areas. Similar to output interfaces of SSEA and MSEA modules, the module provided results in tabular and graphical format as shown in Figure 9c. In addition, output files are provided for download in spreadsheet program for further analysis. 
Figure 9. Tabular and graphical output of Web GIS-based VFSMOD system (a) Output interface of Single Storm Event Analysis (SSEA) module; (b) Output interface of Multiple Storm Event Analysis (SSEA) module; (c) Output interface of HUFF \& SCS UH-based VFS design module.

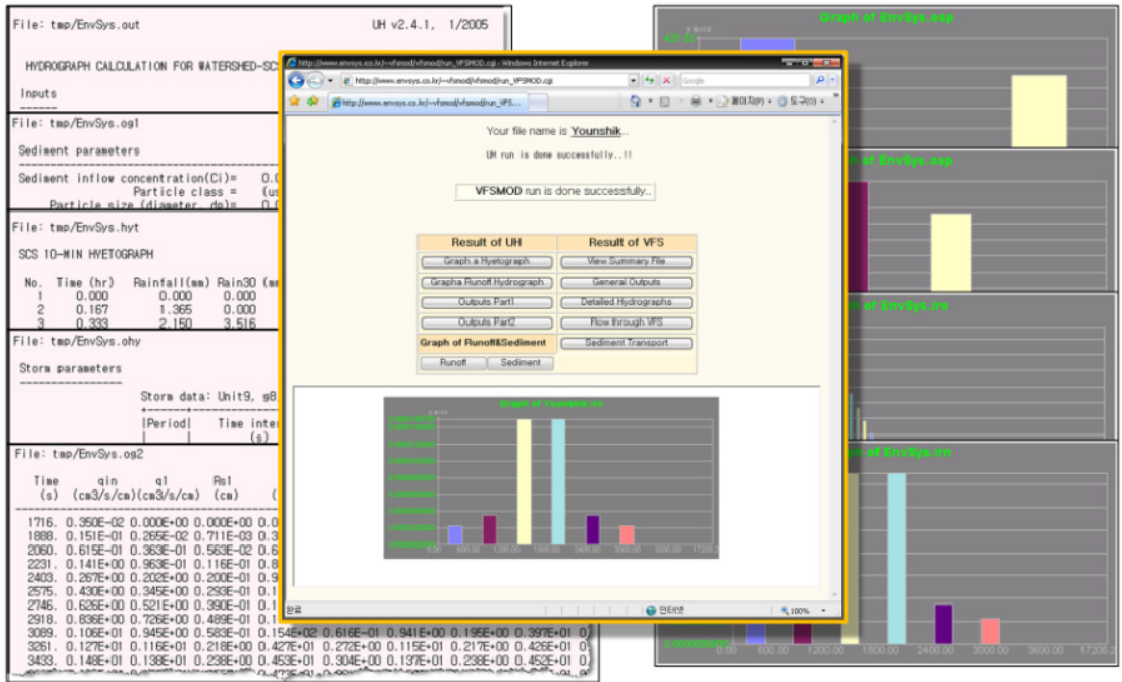

(a)

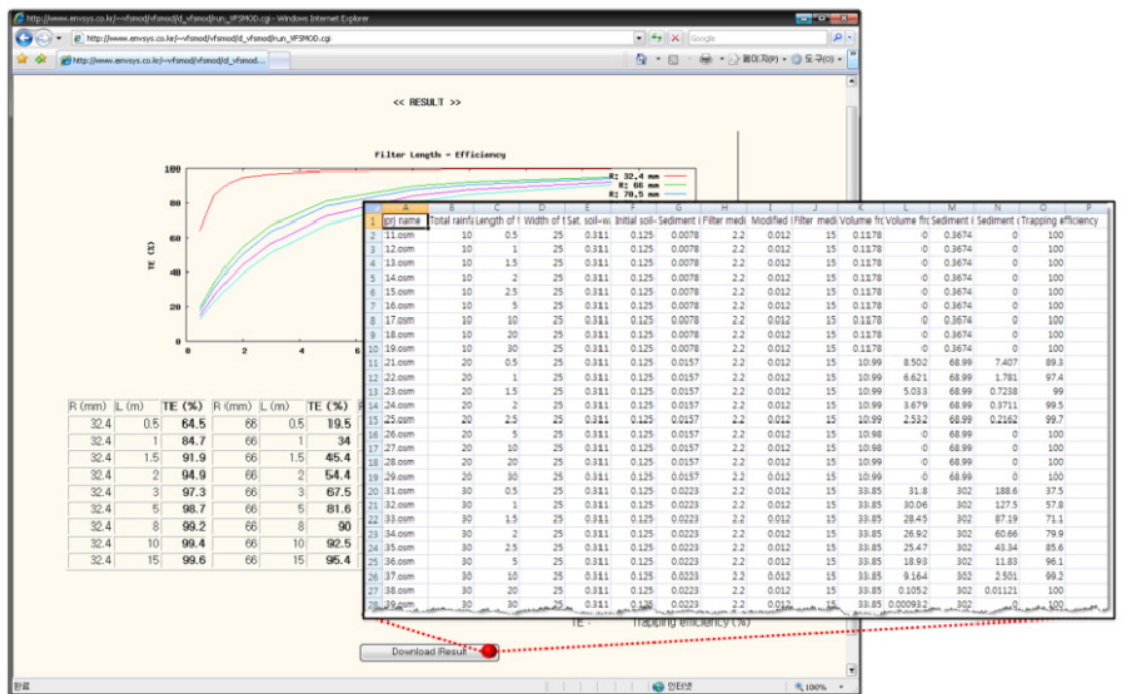

(b)

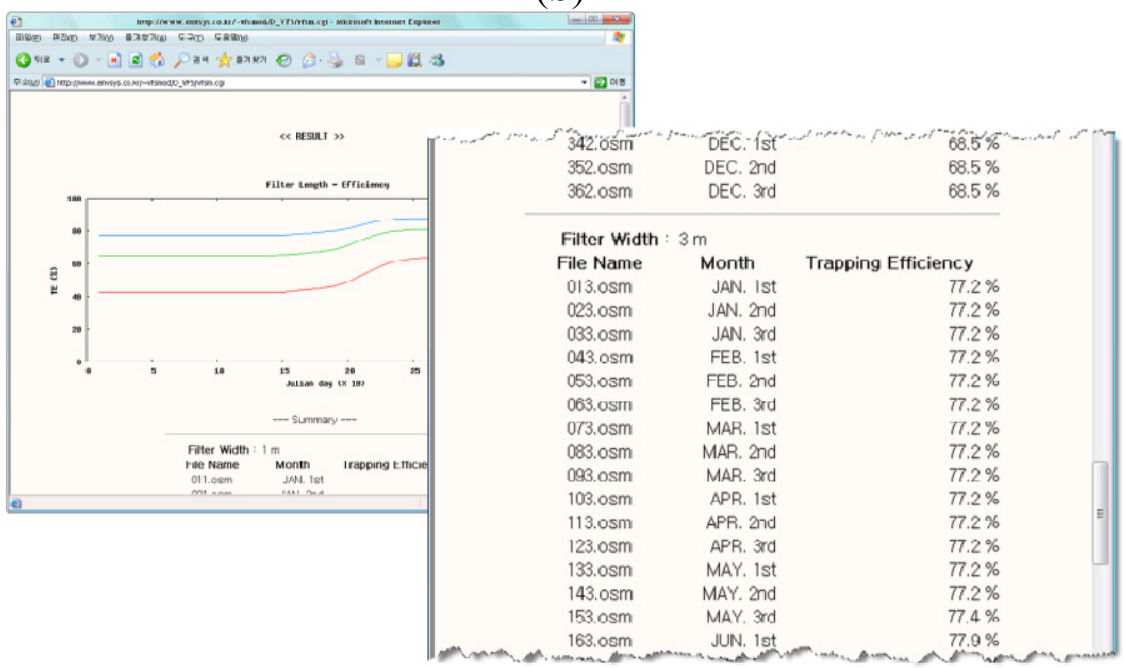

(c) 


\section{Application of Web GIS-Based VFSMOD}

To demonstrate how the Web GIS-based VFSMOD can be used to simulate the trapping efficiency and determine effective VFS width, the Web GIS-based VFSMOD system was applied to an agricultural field of the Su-dong watershed, located at Gangwon Province, South Korea (Figure 10). The area of this agricultural field is 0.5 ha. The field is adjacent to the stream, thus it is deemed that the VFS needs to be installed along the edge of the field to prevent sediment inflow into downstream water bodies.

Figure 10. Location of Su-dong study watershed in South Korea.

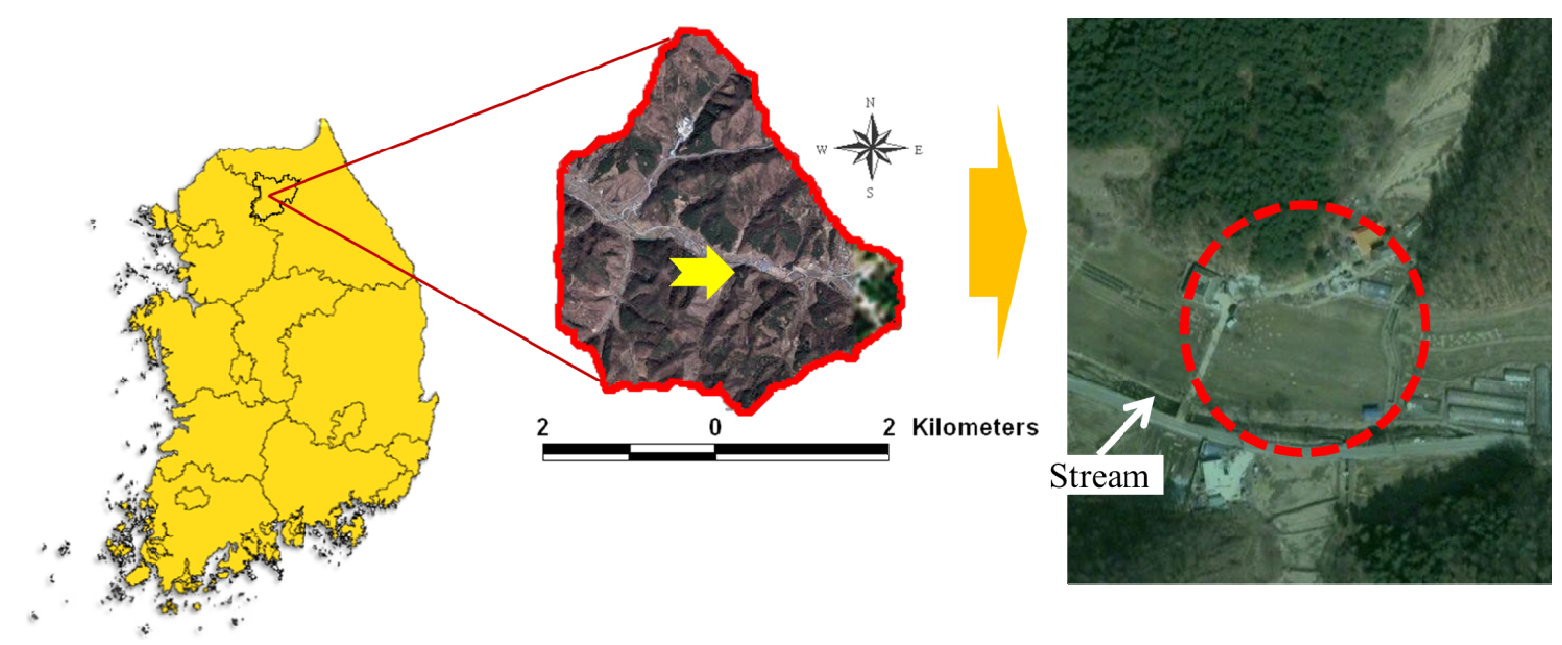

\subsection{Single Storm Event Analysis (SSEA) Module}

To demonstrate the Web GIS-based VFSMOD system performance, two rainfall scenarios were determined. The VFS width of $8 \mathrm{~m}$ under one hour storm duration-100 year return period $(72.6 \mathrm{~mm})$ and source areas of 0.5 ha were simulated for Su-dong watershed. The total amount of rainfall on the VFS of $8 \mathrm{~m}$ width under one hour storm duration, 100 year return period storm event was $31.72 \mathrm{~m}^{3}$, total runoff from the source area was $216.50 \mathrm{~m}^{3}$, total runoff out from the filter was $235.90 \mathrm{~m}^{3}$, total infiltration in the VFS was $12.24 \mathrm{~m}^{3}$ (Figure 11a). The total sediment input to filter was $3679.7 \mathrm{~kg}$; sediment out from filter was $579.0 \mathrm{~kg}$. The $3100.7 \mathrm{~kg}$ of sediment was retained in filter (Figure 11b). This means that only $15.7 \%$ of sediment leaves the filter, with $84.3 \%$ of sediment trapped in the VFS.

\subsection{Multiple Storm Events Analysis (MSEA) Module}

The 5 design storm events for 1 hour duration and 10, 50, 80, 200, and 500 year return period for Chuncheon, South Korea were 32.4, 66.0, 70.5, 79.3, $88.0 \mathrm{~mm}$, respectively [23]. The inputs related to source area were $100 \mathrm{~m}$ for slope length, 0.05 for slope, and 0.5 ha for area. The $\mathrm{C}$ factor value of 0.26 was applied to the agricultural field [24]. The P factor of 0.5 was used. The soil type, particle class diameter, and Green-Ampt Infiltration parameters from the Google Map interface to the Mapserver soil database were used in this run. Nine tall fescue VFS width values of 0.5, 1.0, 1.5, 2.0, 3.0, 5.0, 8.0, 10.0, and $15.0 \mathrm{~m}$ were simulated to examine effective VFS width and trapping efficiency under various 
conditions. It takes approximately 25 minutes to complete "Multiple Storm Events Analysis (MSEA) module" for 45 combinations.

Figure 12 shows that sediment trapping efficiencies for 45 rainfall-VFS width combinations. For the VFS width of $8 \mathrm{~m}$, the trapping efficiency was over $80 \%$. To reduce sediment out from the filter by $50 \%$, it was found that the VFS of at least $3 \mathrm{~m}$ is needed. For 2-year, 10-year, 50-year, 100-year, and 500-year return periods and one hour rainfall events, VFS width of $0.5 \mathrm{~m}, 1.7 \mathrm{~m}, 2.0 \mathrm{~m}, 2.5 \mathrm{~m}$, and $3 \mathrm{~m}$ is needed to expect $50 \%$ of sediment reduction with the VFS installation. For $80 \%$ sediment reduction, $1.0 \mathrm{~m}, 4.5 \mathrm{~m}, 5.0 \mathrm{~m}, 6.5 \mathrm{~m}$, and $8.0 \mathrm{~m}$ VFS are needed under the same condition.

Figure 11. Single Storm Event Analysis (SSEA) output of the Web GIS-based VFSMOD system (8 m VFS width against one-hour duration-100 year Return Period). (a) Total rainfall on filter, total runoff from source area, total runoff out from the Filter, total infiltration in the filter under the given rainfall and VFS width condition; (b) Mass sediment input to filter, mass sediment output from filter, mass sediment retained in filter under the given rainfall and VFS width condition.

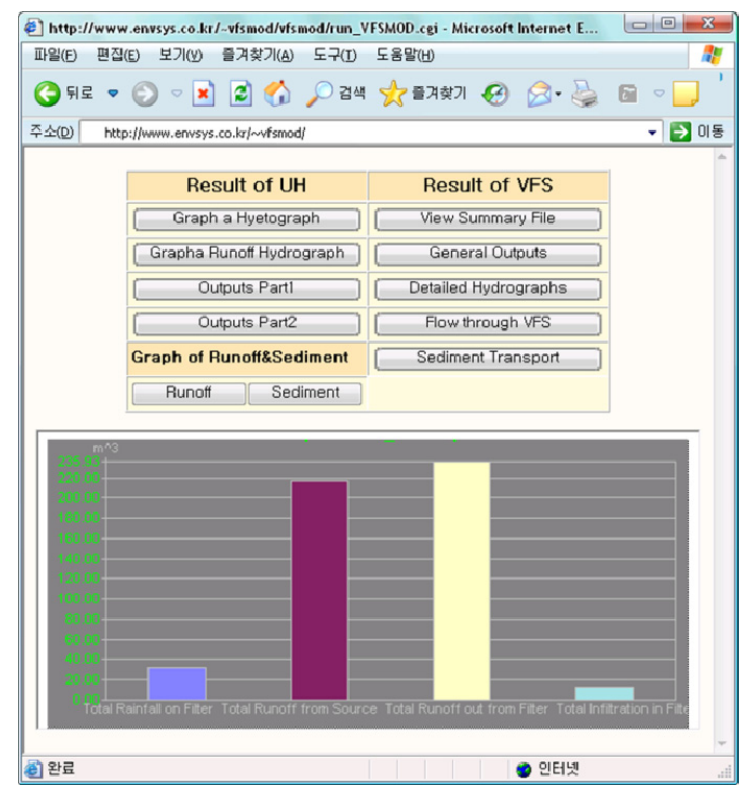

(a)

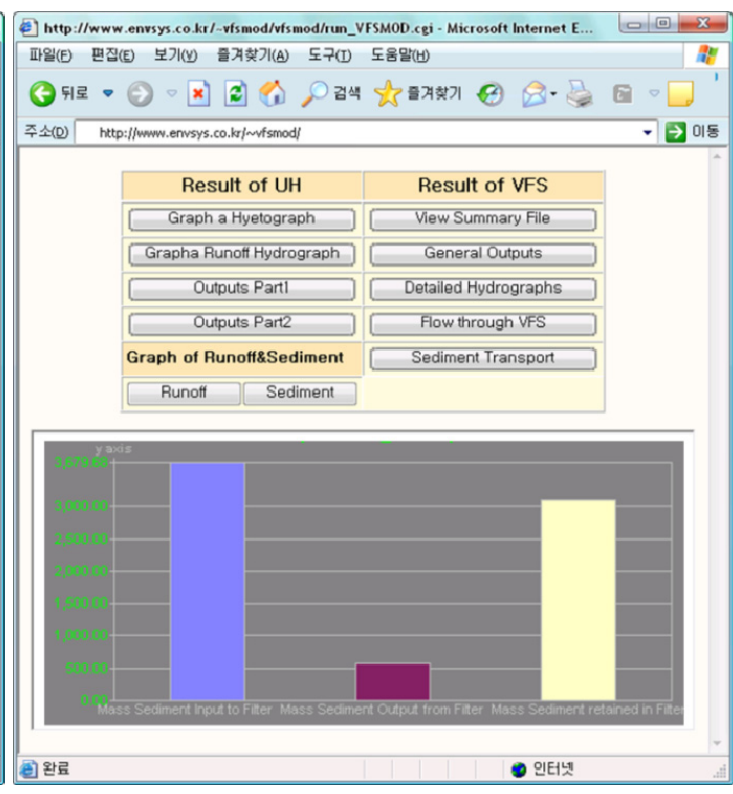

(b)

Figure 12. Trapping efficiency under various design storm event and filter strip width conditions.

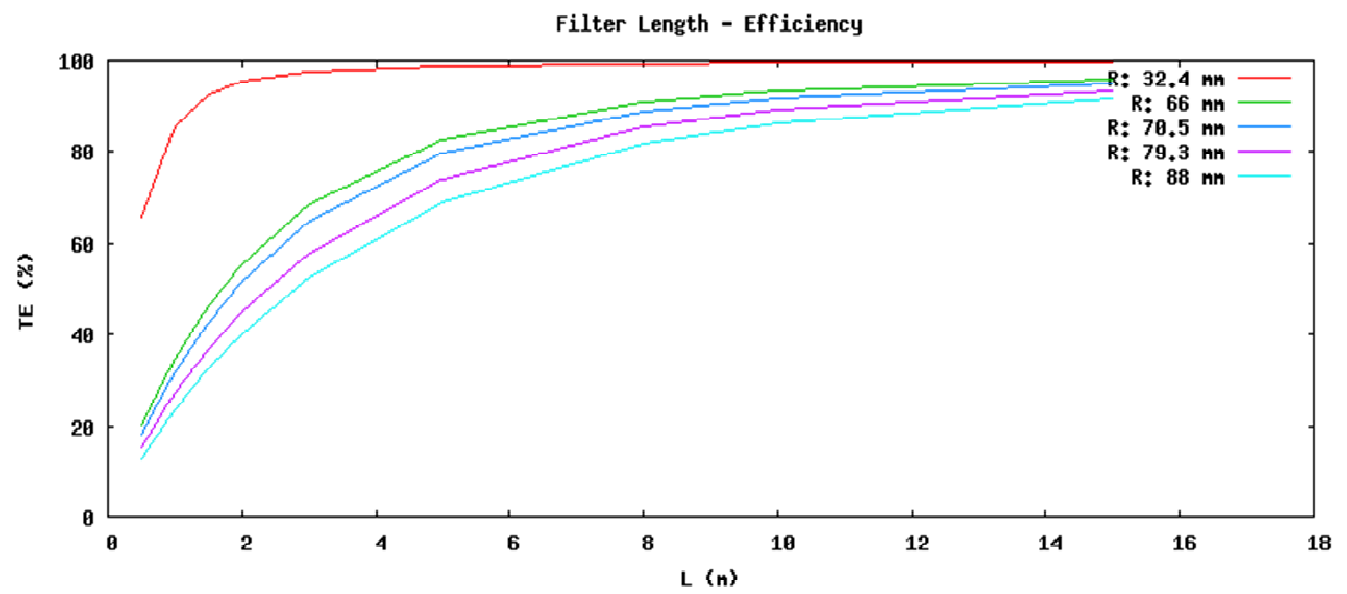




\subsection{Simulation of HUFF \& SCS UH-Based VFS Design Module}

The HUFF \& SCS UH-based VFS Design Module was run with the same input data used in MSEA run, except the rainfall condition of $72.6 \mathrm{~mm}$, one-hour duration-100 years return period design rainfall value for Chuncheon, South Korea. This simulation was conducted under a hypothesis that every factor related with source area and VFS is the same with an exception of crops in source area. In this simulation, the crop of "tomato" was planted at the source area, the maximum trapping efficiency was $87.5 \%$ in September with VFS width of $3 \mathrm{~m}$, and minimum trapping efficiency was $42.4 \%$ in January-June with VFS width of $1 \mathrm{~m}$ (Figure 13).

Figure 13. Trapping efficiency under three filter strip width conditions.

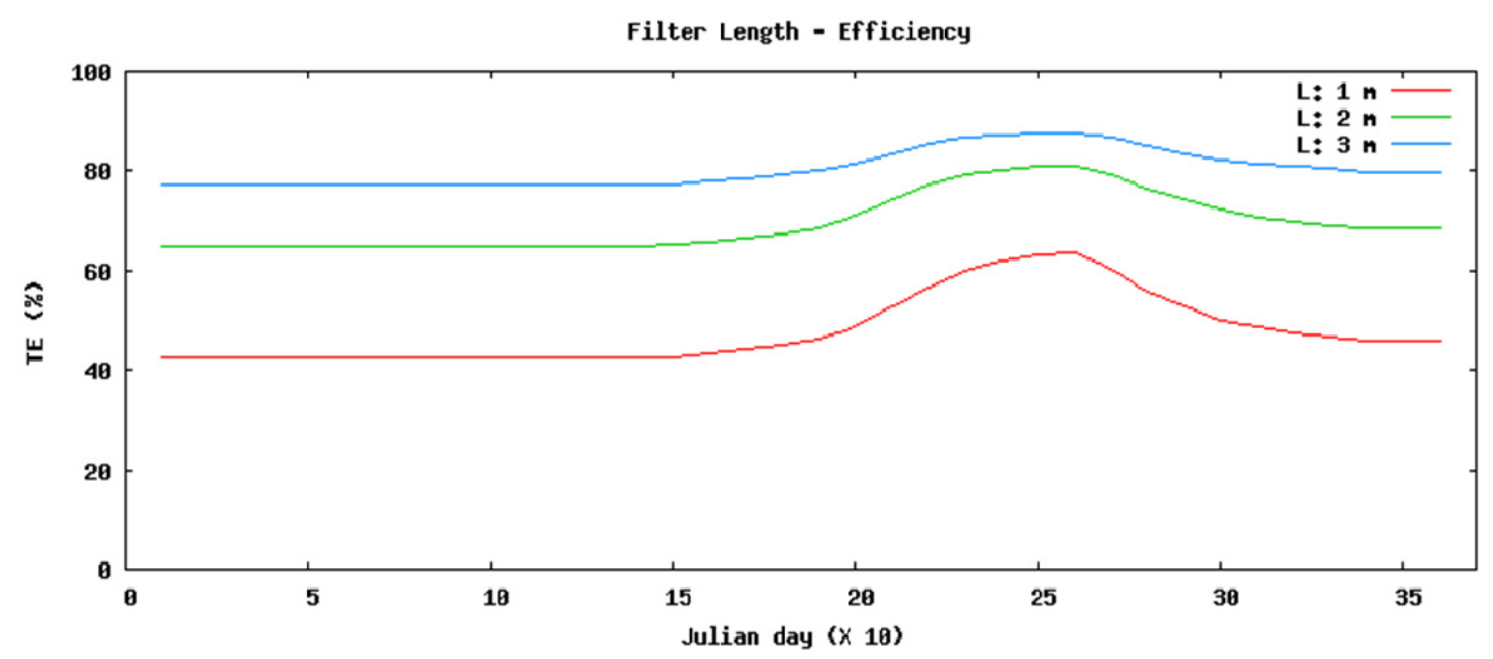

\section{Conclusions}

To provide an easy-to-use interface with a VFS modeling, the Web GIS-based VFSMOD system was developed in this study. The Web GIS-based VFSMOD system is composed of three integrated modules, "Single Storm Event Analysis (SSEA) module", "Multiple Storm Events Analysis (MSEA) module", and "HUFF \& SCS UH-based VFS Design module". With these three modules in the Web GIS-based VFSMOD system, the users can easily simulate the effects of VFS under various rainfall events using the SSEA module, determine effective filter strip width using the MSEA module, and design the VFS width considering crop growth changes in source area using the HUFF \& SCS UH-based VFS Design Module. These three modules were applied to the study watershed located at Gangwon province in South Korea to demonstrate how the Web GIS-based VFSMOD system can be used in VFS analysis. These three modules in the Web GIS-based VFSMOD system have been proved as efficient tools for evaluating and designing the VFS under various field and rainfall conditions.

The Web GIS-based VFSMOD system has several benefits: (1) The system allows user-friendly interfaces via the web to provide convenience for the users; (2) the required input data are provided through the Web GIS database, especially Google Map interface with the Web GIS-based database allowing ease access to the area of concern; (3) the suggested parameters of the VFSMOD-w model are provided; (4) maximum 45 batch runs are allowed in the "Multiple Storm Events Analysis Module" for effective VFS width design with ease-of-interface; and (5) "HUFF \& SCS UH-based VFS Design 
Module" allows consideration of temporal changes of cropping at the source area in a year. The web system is expected for a decision-supporting tool to design VFS.

\section{Acknowledgements}

This research was supported by the GAIA project (No: 2012000540001) in Korea.

\section{References}

1. Brown, L.R. Conserving Soils. In State of the World; Brown, L.R., Ed.; Norton: New York, NY, USA, 1984; pp. 53-75.

2. Muñoz-Carpena, R.; Parsons, J.E.; Gilliam, J.W. Modeling hydrology and sediment transport in vegetative filter strips and riparian areas. J. Hydrol. 1999, 214, 111-129.

3. Arora, K.; Mickelson, S.K.; Baker, J.L.; Tierney, J.L.; Peters, C.J. Herbicide retention by vegetative buffer from runoff under natural rainfall. Trans. Am. Soc. Agric. Eng. 1996, 39, 2155-2162.

4. Dillaha, T.A.; Reneau, R.B.; Mostaghimi, S.; Lee, D. Vegetative filter strip for agricultural nonpoint source pollution control. Trans. Am. Soc. Agric. Eng. 1989, 32, 491-519.

5. Gharabaghi, B.; Whiteley, H.R.; Dickinson, W.T. Sediment removal efficiency of vegetative filter strips. Trans. Am. Soc. Agric. Eng. 2001, 32-40.

6. Tarantilis, C.D.; Kiranoudis, C.T.; Theodorakopoulos, N.D. A Web-based ERP system for business services and supply chain management: Application to real-world process scheduling. Eur. J. Oper. Res. 2008, 187, 1310-1326.

7. Lim, K.J.; Engel, B.A. Extension and enhancement of national agricultural pesticide risk analysis (NAPRA) WWW decision support system to include nutrients. Comput. Electron. Agric. 2003, 38, 227-236.

8. Lim, K.J.; Engel, B.A.; Tang, Z.; Choi, J.; Kim, K.S.; Muthukrishnan, S.; Tripathy, D. Automated web GIS based hydrograph analysis tool, WHAT. J. Am. Water Resour. Assoc. 2005, 1407-1416.

9. Web GIS-based VFSMOD system. Available online: http://www. EnvSys.co.kr/ vfsmod (accessed on 30 July 2013).

10. Mersie, W.; Seybold, C.A.; McNamee, C.M.; Huang, J. Effectiveness of switchgrass filter strips in removing dissolved atrazine and metolachlor from runoff. J. Environ. Qual. 1999, 2, 816-821.

11. Fox, G.A.; Muñoz-Carpena, R.; Sabbagh, G.J. Influence of flow concentration on parameter importance and prediction uncertainty of pesticide trapping by vegetative filter strips. J. Hydrol. 2010, 384, 164-173.

12. White, M.J.; Arnold, J.G. Development of a simplistic vegetative filter strip model for sediment and nutrient retention at the field scale. Hydrol. Process. 2009, 23, 1602-1616.

13. Muñoz-Carpena, R.; Parsons, J.E. VFSMOD, Versoin 2.x. User's Maunal; Gainesville, FL, USA, 2005; pp. 2-9.

14. Muñoz-Carpena, R.; Fox, G.A.; Sabbagh, G.J. Parameter importance and uncertainty in predicting runoff pesticide reduction with filter strips. J. Environ. Qual. 2010, 39, 630-641. 
15. Fox, L.A.; Dean, E.E.; Michael, G.D. Modeling Water and Sediment Trapping by Vegetated Filter Using VFSMOD: Comparing Methods for Estimating Infiltration Parameters. In Proceedings of ASAE Annual International Meeting, Tampa, FL, USA, 17-20 July 2005; pp. 2-14.

16. Muñoz-Carpena, R.; Miller, C.T.; Parsons, J.E. A quadratic Petrov-Galerkin solution for kinematic wave overland flow. Water Resour. Res. 1993, 29, 2615-2627.

17. Abu-Zreig, M. Factors affecting sediment trapping in vegetated filter strips: Simulation study using VFSMOD. Hydrol. Process. 2001, 15, 729-742.

18. Arnold, J.G.; Srinivasan, R.; Muttiah, R.S.; Williams, J.R. Large area hydrologic modeling and assessment part I: Model development. J. Am. Water Resour. Assoc. 1998, 34, 73-89.

19. Park, Y.S.; Park, J.H.; Jang, W.S.; Ryu, J.C.; Kang, H.; Choi, J.; Lim, K.J. Hydrologic response unit routing in swat to simulate effects of vegetated filter strip for south-Korea conditions based on VFSMOD. Water 2011, 3, 819-842.

20. Muñoz-Carpena, R.; Parsons, J.E. A design procedure for vegetative filter strips using VFSMOD-W. Trans. Am. Soc. Agric. Eng. 2004, 47, 1933-1941.

21. Geo-Proj4 module. Available online: http://search.cpan.org/dist/Geo-Proj4/ (accessed on 30 July 2013).

22. Park, Y.S.; Kim, J.; Kim, N.W.; Kim, S.J.; Jeon, J.H.; Engel, B.A.; Jang, W.S.; Lim, K.J. Development of new R, C, and SDR modules for the SATEEC GIS system. Computers Geosci. 2010, 26, 726-734.

23. Ministry of Construction and Transportation. 1999 Research of Water Resource Management Development. Presented at Regulation of Probabilistic Rainfall in Korea, Gyeonggi-do, South Korea, 2000.

24. Jung, P.K.; Ko, M.H.; Um, K.T. Discussion of cropping management factor for estimating soil loss. Korean Soc. Soil Sci. Fertilizer. 1985, 18, 7-13.

(C) 2013 by the authors; licensee MDPI, Basel, Switzerland. This article is an open access article distributed under the terms and conditions of the Creative Commons Attribution license (http://creativecommons.org/licenses/by/3.0/). 